\title{
Educação de adultos na educação ao longo da vida: desenvolvimentos atuais e interdependentes na Alemanha e na Europa, a caminho da VI CONFINTEA
}

\author{
Heribert Hinzen \\ Instituto para Cooperação Internacional da Associação Alemã de Educação de Adultos
}

Tradução: Alexandre Fernandez Vaz

\section{Introdução}

Procurarei mostrar, tomando como exemplo alguns documentos e congressos, organizações e personagens, como nos últimos anos foi posto em movimento um acelerado e intensivo intercâmbio de ideias, concepções e modelos sobre a educação de adultos que ultrapassam fronteiras no contexto de uma recíproca influência entre teoria e prática.

Destaco de início dois textos como especialmente interessantes para esta reflexão. O primeiro é o de Wolfgang Seitter (2000), que em "A educação de adultos na Alemanha em contexto internacional” investigou e propôs a “internacionalização como horizonte”, apontando que se coloca com vigor a tese de que a educação de adultos, em seus períodos de constituição, muito deveu a imagens, modelos e instituições estrangeiros, algo que foi sobremaneira reforçado por sistemáticos contatos acadêmicos e pessoais. Ele pontua como um primeiro exemplo o período entre 1890 e 1930, quando a extensão universitária inglesa, as escolas superiores populares da Dinamarca e as bibliotecas públicas norteamericanas serviram como modelo para as escolas superiores populares (Volkshochschulen) e bibliotecas populares (Volksbüchereien). Da mesma forma, a educação de adultos entre 1960 e 1975 modernizou-se e profissionalizou-se, no contexto da reforma pedagógica, como um programa internacional. Para isso, adaptou conceitos norteadores - como aprendizagem ao longo da vida (lifelong learning), educação recorrente (recurrent education) e educação permanente (éducation permanente) - que foram depois, de forma muito oportuna, lançados pela Organização das Nações Unidas para a Educação, a Ciência e a Cultura (UNESCO) e pela Organização para Cooperação e Desenvolvimento Econômico (OCDE), compondo argumentos relacionados à economia e à democratização da educação.

$\mathrm{O}$ outro texto é de autoria de Joachim H. Knoll (2008). Ele já havia antecipado uma série de questões em "Para uma história da Conferência Mundial de Educação de Adultos da UNESCO - de Helsingör (1949) a Hamburgo (1997): políticas internacionais de formação em pessoas e programas”. Algumas delas referem-se a como nascem as políticas de formação ao longo do tempo e como são levadas em conta pelos organismos e pelas pessoas. São poucos os que, como Knoll, são capazes de 
se ocupar de maneira profunda e em perspectiva comparada com essas questões em âmbito nacional, europeu e internacional, considerando décadas do processo. Além disso, em grande medida, ele foi não apenas testemunha desse processo mas, vivendo-o, escreveu e ajudou a dar forma à história da educação de adultos.

Paul Bélanger lembrava, em reunião do grupo consultivo para a VI Conferência Internacional de Educação de Adultos (CONFINTEA VI), em junho de 2008, sua presença na Conferência Mundial da UNESCO em 1960, e, depois dela, em todas as seguintes. Esse é um fato digno de nota, uma vez que Bélanger foi diretor do Instituto para a Educação Permanente da própria UNESCO, em Hamburgo, durante os anos de 1990; nessa condição, fora o arquiteto da última e até então maior conferência, a de 1997. Desde 2000, preside o Conselho Internacional para a Educação de Adultos (ICAE) e voltou a ser professor titular da Universidade de Montreal.

A contribuição da presente reflexão é mais modesta, abarcando apenas os três últimos anos do processo. Tomando um exemplo localizado, o da Alemanha, visto no entanto como uma posição continental por sua importância para a União Europeia - talvez, aliás, recíproca -, procurarei verificar, desde o pré-conferência da Hungria, como se configura o processo que nos leva até a próxima CONFINTEA VI, no Brasil.

\section{Conferência regional para a CONFINTEA VI}

AUNESCO clama há doze anos pela participação em uma nova CONFINTEA. Em 1997 aconteceu a V CONFINTEA, em Hamburgo, da qual se originaram dois importantes documentos: a "Carta de Hamburgo para o aprendizado na idade adulta” e a "Agenda para o futuro". A Escola Superior Popular de Hamburgo e a Federação das Escolas Superiores Populares da Alemanha (DVV) eram, naquele tempo, parceiros muito ativos. A professora ${ }^{1}$ Rita Süssmuth foi a presidente

${ }^{1}$ N. T.: Toda vez que a designação professor ou professora for empregada, refere-se ao título de professor titular na Alemanha (Profesor ou Profesorin) e não a professor ou professora de outro nível de ensino. eleita do congresso e conduziu com muito sucesso as frequentemente difíceis rodadas de negociação (UNESCO, s.d.). Muitos membros da DVV tomaram parte do evento.

O processo preparatório para a VI CONFINTEA vem acontecendo desde 2007, quando o Instituto para a Aprendizagem ao Longo da Vida, da UNESCO, criou um grupo de trabalho específico, a partir do qual tudo começou a ser gerado, desde o "Relatório Global sobre a Aprendizagem e a Educação de Adultos” (Global Report on Adult Learning and Education - GRALE), passando pelas conferências regionais e chegando ao encontro mundial, "Vivendo e aprendendo para um futuro viável - o poder da aprendizagem de adultos" (Living and Learning for a Viable Future - The Power of Adult Learning), previsto inicialmente para ser realizado em maio de 2009, em Belém, no Brasil (UNESCO, s.d.).

A conferência regional para a Europa, América do Norte e Israel foi realizada na Hungria entre 3 e 5 de dezembro de 2008. A CONFINTEA é classificada pela UNESCO na categoria 2 e, como tal, é considerada uma conferência intergovernamental, exigindo a preparação de relatórios nacionais e um documento final da conferência, todos de caráter obrigatório.

Para a conferência europeia, vieram delegações - que deveriam ser constituídas por representantes da sociedade civil e por especialistas em diferentes áreas - de trinta e três países. A alemã, liderada por Oliver S. Lübke, do Ministério da Educação e da Pesquisa (Bundesministerium für Bildung und Forschung $\mathrm{BMBF}$ ), foi composta por dez pessoas, entre elas Ulla Burchardt, do Parlamento alemão, e representantes da Conferência de Ministros de Cultura (Kultusministerkonferenz - KMK), da Confederação de Sindicatos Alemãos (Deutscher Gewerkschaftsbund - DGB) e da Associação de Câmaras Alemães de Indústria e Comércio (Deutscher Industrie- und Handelskammertag - DIHK), Instituto Alemão de Educação de Adultos (Deutsches Institut für Erwachsenenbildung - DIE) e Comissão Alemã da UNESCO (Deutsche UNESCO-Kommission - DUK). A presidente da DVV, Rita Süssmuth, proferiu a palestra de abertura, enquanto o professor Dieter Timmermann, que havia 
dirigido a comissão de especialistas para o financiamento da educação ao longo da vida, apresentou na plenária da conferência as opções de financiamento disponíveis no caso alemão. Heribert Hinzen foi convocado para participar do comitê de redação do documento final. Como organização reconhecida pela UNESCO, a DVV International enviou uma delegação própria, que tomou parte do evento de maneira bastante ativa; entre seus membros estava grande número de diretores de seus departamentos no exterior. Destaque-se ainda a presença de Uwe Gartenschlaeger, como representante da direção do instituto, bem como do professor Joachim H. Knoll, membro da curadoria.

Apresento a seguir algumas citações do PanEuropean statement on adult learning for equity and inclusion in the context of mobility and competition que se referem principalmente à política de educação de adultos, no que diz respeito à legislação e ao financiamento. No texto adota-se a sigla ALE para Adult Learning and Education, ou seja, uma referência que sintetiza os aspectos formais e não-formais da educação de adultos:

5. AALE exerce um papel crítico ao se colocar frente a esses desafios econômicos, socioculturais, políticos e educacionais, e desde a V Confintea se pode observar notáveis ganhos para a ALE em diversas frentes. Tanto a União Europeia quanto a OECD reconhecem a centralidade da educação ao longo da vida [...]. Políticas para a ALE estão presentes em quase todos os países da região.

7. São relevantes as redes já existentes e a capacidade da ALE em responder a desafios diversificados, conforme o país. Em um pequeno número de países, a resposta tem sido prioritariamente dirigida à educação vocacional e à qualificação com vistas ao crescimento e ao aumento da competitividade. No entanto, a perspectiva geral da Conferência é de que há necessidade de uma abordagem mais integrada vinculada a desenvolvimento econômico, coesão social, igualdade e diversidade, cidadania democrática, desenvolvimento sustentável, desenvolvimento pessoal e comunitário.

11. As atenções governamentais devem se dedicar à formação de redes, estruturas e parcerias locais, regionais e na- cionais - incluindo autoridades públicas, parcerias sociais e sociedade civil -, essenciais para o desenvolvimento, coordenação, financiamento, administração e monitoramento da qualidade da ALE. O envolvimento da sociedade civil na definição de políticas e em sua implementação e administração deve ser particularmente promovido e apoiado.

12. Fundos públicos mais vultosos são uma chave para o desenvolvimento da $A L E$, algo vital tanto para os interesses públicos quanto privados. Em muitos países o financiamento da educação vocacional de adultos, e particularmente a não vocacional, é insuficiente.

13. Os fundos deveriam incluir recursos públicos oriundos de fontes nacionais, estaduais e municipais, assim como contribuições de múltiplos parceiros, tanto individuais quanto do setor privado. Grupos marginalizados apresentam necessidades especiais de apoio. Os investimentos oportunos e efetivos na ALE poderiam prever os enormes custos sociais do desemprego e da marginalização.

14. Devem ser criados novos mecanismos de financiamento, de forma a estimular a participação individual e coletiva, bem como o investimento do setor empresarial.

18. Resultados de aprendizagem devem ser reconhecidos e validados, independentemente de onde, quando e como foram obtidos, o que precisa ser feito considerando os contextos nacionais e regionais.

19. É necessário o desenvolvimento de políticas, estruturas e mecanismos de avaliação para assegurar a qualidade do ensino. (UNESCO, s.d., grifos meus)

As questões relacionadas à política, à legislação e ao financiamento foram as mais intensivamente debatidas nos grupos de trabalho e no comitê responsável pela elaboração do documento final. Foi o caso, por exemplo, da insuficiência da formulação original do financiamento público básico (core public funding) para a educação de adultos, principalmente em relação àqueles Estados que assumem o mercado como matriz de seu funcionamento.

Dignas de nota também são as diversas faces do desenvolvimento global, considerando não apenas a aguda crise financeira e econômica e suas implicações sociais (e educacionais) mas também a responsabilidade que os países que se fortaleceram com a globa- 
lização têm com outras regiões do planeta: "É muito importante que a região pan-europeia reconheça sua responsabilidade como parceira no desenvolvimento da ALE no restante do mundo. O significado da parceria Norte-Sul já foi extremamente debatido e já se sabe das possibilidades do aprendizado mútuo, da contribuição para que se alcance as metas da Educação para Todos e da importância da ALE para chegar aos objetivos de desenvolvimento do milênio”.

Em preparação para a conferência, Helen Keogh elaborou o relatório regional oficial intitulado " $\mathrm{O}$ estado o desenvolvimento da aprendizagem e educação de adultos na Europa, América do Norte e Israel” (The state and developemnt of adult learning and education in Europe, North America and Israel), oferecendo uma ótima visão sobre o tema. Os primeiros dois capítulos se dedicam a descrever como a ALE se organiza administrativamente e quais são suas fontes de recursos financeiros. O ponto de partida foram os diagnósticos de cada país (mais de 150 relatórios nacionais foram apresentados à UNESCO como parte do processo preparatório), analisados e apresentados por um método adotado pelo Grupo Consultivo da VI CONFINTEA. ${ }^{2}$ Foi difícil, no entanto, com tal método, alcançar processos e resultados em cada especificidade nacional; tampouco foi fácil desenvolver análises comuns que levassem a uma perspectiva comparada. Na Alemanha foram representativas desse processo a BMBF e a KMK. Essas entidades propuseram ao Instituto Alemão de Educação de Adultos (DIE) a elaboração de um relatório que incluiria a participação de importantes organizações e especialistas em educação de adultos da Alemanha. É importante destacar que o documento foi redigido por Susanne Lattke. Estavam em questão as expectativas ante a VI CONFINTEA, o atual estágio da teoria e da prática da educação de adultos e o desenvolvimento político e as correspondentes necessidades de ação. Uma oficina, cujo tema foi a preparação de relatórios, foi oferecida pela Comissão Alemã da UNESCO (DUK).

${ }^{2} \mathrm{O}$ método está disponível na página web da UNESCO.
Os resultados são visíveis. Publicou-se um volume com mais de 250 páginas, em alemão e inglês, intitulado "Desenvolvimento e estado da arte da aprendizagem e educação de adultos - Relatório da Alemanha", cujos temas centrais são os aspectos legais e políticos, de organização e sustentação, financiamento, oferta e participação, garantia da qualidade e estabelecimento de pontos de referência (benchmarking), pesquisa e formação continuada. Finalmente temos novamente um relatório com o qual não nos envergonhamos de entrar em um debate internacional. ${ }^{3}$

\section{A posição da Cúpula de Educação (Bildungsgipfel)}

O debate político-pedagógico com vistas à materialização de um amplo sistema de educação ao longo da vida na Alemanha intensificou-se nos últimos anos. Ele insere-se na progressiva busca pelo avanço em todos os níveis de ensino, bem como na superação da hodierna situação econômica. Para tanto, colocou-se na Cúpula de Educação (Bildungsgipfel) o tema "Iniciativas de qualificação para a Alemanha - progresso pela educação”, resultado da convergência de posições tanto da primeira-ministra Angela Merkel quanto dos governos de cada estado alemão. Coloca-se, nesse movimento, o conceito de "República da Educação". ${ }^{4}$

A Associação Alemã de Escolas Superiores Populares (Deutscher Volkshochschul-Verband - DVV) alcançou seu espaço por meio de diversas iniciativas. Em um manifesto, ${ }^{5}$ ela afirma que "a educação continuada exerce um papel central sobre o currículo de uma pessoa". A palavra-chave "globalização", as “fortes mudanças tecnológicas”, a "participação na vida profissional e social" conduzem ao "importante significado da educação continuada para o desenvolvimento individual, econômico e social na Alemanha está, há muito tempo, demonstrado cientificamente".

${ }^{3} \mathrm{O}$ documento pode ser solicitado em www.bmbf.de.

${ }^{4}$ Bildungsrepublik, República da Educação, é um trocadilho com Bundesrepublik, República Federal (da Alemanha).

${ }^{5}$ Disponível em www.dvv-vhs.de. 
Como tarefas urgentes colocam-se as seguintes questões, claramente orientadas para pontos nevrálgicos das políticas europeias e internacionais que visam ao fortalecimento da educação de adultos:

1. Segunda chance por meio da educação continuada

[...] cada adulto deve, independente de sua renda, ter a chance de recuperar a alfabetização insuficiente, assim como a conclusão da escola, de um curso superior ou de formação profissional [...]

2. Mais apoio à educação depois dos 30 anos de idade

AAlemanha precisa, para a educação de adultos, de um sistema de financiamento transparente, consistente e com objetivos claros, que vise especialmente às camadas mais distantes dos processos formativos, empregadas em uma nova profissão.

\section{Acesso universal}

A educação continuada só se materializa quando os governos federal, estaduais e municipais assumem plenamente a oferta de educação de adultos em seus aspectos político, cultural e profissional, com responsabilidade pública. A nenhum segmento social deve ser negado, por questões econômicas, o acesso à educação de adultos.

4. $6 \%$ do orçamento educacional para a educação de adultos

No contexto de sua política de apoio à educação continuada (do "Memorando sobre a educação continuada”, de 2000, até o "Plano de ação”, de 2007), a União Europeia considera a educação de adultos uma questão singular e altamente estratégica. A estrutura de financiamento da educação de adultos na Alemanha deve, no futuro, orientar-se no desenvolvimento europeu e no estabelecimento de padrões de referência internacionais. A educação continuada deveria avançar até o ponto de poder ser contemplada com $6 \%$ dos recursos destinados à educação de adultos, incluindo-se aí a alfabetização e a educação básica. Com esses recursos, talvez fosse possível chegar ao objetivo da "Década da Alfabetização”, conforme preconizada pelas Nações Unidas, que é a diminuição à metade, até 2015, do contingente atual de analfabetos.

5. Condições estruturais permanentes para a educação continuada

Na procura pela qualidade e considerando as expectativas para a educação continuada, é preciso que os governos federal, estaduais e municipais, a exemplo do que acontece com o sistema escolar, atuem de forma conjunta e articulada. Questões a serem regulamentadas seriam, entre outras, a garantia de acesso e incremento da qualidade, certificação (inclusive daquelas competências desenvolvidas de maneira informal), planejamento do tempo de formação.

A curto prazo, é possível dar-se por satisfeito se as exigências legais da educação continuada pudessem compor o debate político, ainda que isso não seja, obviamente, suficiente. O professor Peter Faulstich, por exemplo, pesquisador do campo da educação e por longos anos presidente da Sociedade Alemã para a Pesquisa em Educação Continuada e Educação a Distância, de Hamburgo, mostrou toda sua decepção ao avaliar que a Cúpula de Educação (Bildungsgipfel) seria pouco mais de um montículo de terra feito por toupeiras (Maulwurfhügel). ${ }^{6}$

\section{Conselho da União Europeia:} declaração sobre a educação de adultos

No início desse texto abordei as questões no âmbito da Comunidade Europeia, vanguarda no desenvolvimento de um sistema de educação de adultos

6 http://www.bildungsspiegel.de/aktuelles/bildungsgipfelein-maulwurfhuegel.html. 
no contexto da educação continuada. O processo começou com a Declaração de Lisboa, que destaca o papel da educação na modernização e no incremento da competitividade na esfera econômica, e vai até o último Manifesto para o Sistema de Qualificação na Europa (EQF). Procurava-se o desenvolvimento de uma estrutura unificada, com indicadores e pontos de referência (benchmarking), assim como a validação dos resultados da educação não-formal.

Até agora, puderam ser conhecidas apenas algumas das consequências desse difícil caminho: qualificação mais alta de trabalhadores com competências profissionais insuficientes, redução da alta evasão escolar, baixa qualidade da escola básica. Essas são condições irrenunciáveis para que se alcance a inclusão, participação e empregabilidade. Nesse sentido, o conselho aponta as seguintes medidas:

1. o apoio efetivo à educação deve ser considerado prioritário, em nível nacional, como parte do esforço geral de desenvolvimento de uma cultura de educação ao longo da vida; [...]

5. o caráter interdisciplinar, diverso, complexo e rico da educação de adultos impõe a necessidade de uma abordagem integrada que possa envolver os interessados, tanto em nível local quanto regional, as parcerias sociais e as organizações não-governamentais.

A Comissão da União Europeia sugere, ainda, "buscar e intensificar a cooperação com organizações internacionais e com instituições não-governamentais que atuem nesse campo, assim como estabelecer vínculos com iniciativas de largo alcance mundial, como a Educação para Todos e os Objetivos de Desenvolvimento do Milênio".

Junto a isso, exige-se dos Estados-membros, como medidas específicas:

9. Realizar esforços para assegurar uma quota adequada de recursos para a educação de adultos, considerando os vários setores da educação e em consonância com uma abordagem de educação ao longo da vida. (Council of the European Union, 2008)

\section{Posição do governo federal alemão sobre a educação de adultos}

O Ministério da Educação e da Pesquisa (BMBF) apresentou ao Parlamento, em 6 de maio de 2008, um documento intitulado Posição do governo alemão sobre a educação de adultos. Mais especificamente, o documento foi apresentado à Comissão de Educação, Pesquisa e Desenvolvimento Técnico, na qual se destaca a deputada Ulla Burchardt.

O BMBF havia criado um grupo de trabalho para a construção de propostas de inovação para educação continuada. Para ele, representando a DVV, foram convocados os professores Rita Süssmuth e Klaus Meisel. As proposições elaboradas pelo grupo ofereceram as bases para a posição do governo alemão, começando com a seguinte afirmação:

\begin{abstract}
A educação de adultos está entre as mais importantes exigências políticas e sociais na Alemanha. A materialização da educação de adultos é decisiva para as perspectivas individuais, para o desenvolvimento da economia e para o futuro da sociedade [...]. A globalização e a sociedade do conhecimento desafiam a humanidade com grandes exigências, que se avolumam ainda mais com a transformação demográfica da sociedade: conhecer, assim como a capacidade de empregar o conhecimento desenvolvido, devem ser continuamente adaptadas e estendidas.
\end{abstract}

Nas páginas seguintes, o texto ocupa-se do significado da educação para a empregabilidade, do engajamento da sociedade civil e da integração de homens e mulheres com histórico migratório. Ambiciona-se chegar à “educação ao longo da vida”, com ampliação do número de participantes, programas e medidas de incentivo. Não se deve ter ilusões, no entanto, em relação a mais recursos financeiros:

Esses objetivos exigem considerável esforço, que ultrapassa os atuais instrumentos de financiamento da educação ao longo da vida. Nesse contexto, é importante destacar a responsabilidade dos empresários, cujo engajamento deve ser estimulado e apoiado. Também é importante a diminuição 
de taxas e a participação social na educação continuada nas empresas. (BMBF, s.d.)

Um objetivo central é o aumento do número de pessoas com idade entre 25 e 64 anos matriculadas nos programas de educação ao longo da vida, isto é, passar dos atuais 43 para $50 \%$. Isso exige principalmente a incorporação de homens e mulheres com baixa qualificação, exatamente os que dela menos participam.

Essa concepção incorpora um sem-número de medidas e propostas concretas a serem implementadas. Muitas delas se referem ao aumento dos recursos de financiamento, que individualmente alcançam diferentes motivações e que devem melhorar as possibilidades de acesso. Pontos importantes desse movimento são a instituição de um prêmio, ${ }^{7}$ período de estudos adequado ao trabalho, bolsas de incentivo e aprovação de uma lei de apoio ao desenvolvimento da carreira profissional. Além disso, a melhoria nos processos de aconselhamento educacional é um elemento decisivo para o sucesso dessa empreitada. ${ }^{8}$

A Comissão de Educação do Parlamento Alemão intensificara o debate sobre o financiamento da educação de adultos no contexto da educação ao longo da vida em uma audiência de janeiro de 2007. As questões 20 e 21 - que se referem ao potencial de uma legislação de apoio à educação de adultos, assim como à educação de adultos como direito - foram suficientes para que a DVV tivesse melhores possibilidades de reivindicar o que havia de mais urgente no apoio às escolas populares superiores (DVV, 2007).

\section{Plano de Ação para a Educação de Adultos e Educação de Adultos: a formação profissional não tem fim}

Em 2000 foi publicado pelo Departamento Central de Cultura e Educação da Comissão da Comunidade Europeia um importante memorando sobre a

${ }^{7}$ N. T.: Trata-se de uma soma em dinheiro destinada à formação individual. Sobre o tema, ver http://www.bildungspraemie.info.

${ }^{8}$ Consulte-se www.bmbf.de. educação ao longo da vida, que alcançou expressiva circulação entre os países membros, tendo sido reelaborado várias vezes. Como epígrafe do texto, encontramos o ditado chinês: "Se você tem no horizonte um ano, semeie milho. Se ele for de dez anos, então plante uma árvore. Mas se ele for de cem anos, então eduque um ser humano". ${ }^{9}$

É importante, nesse processo, compreender que a educação de adultos exerce um papel crescente de estender, descentralizar, ter efeito em espaços de aprendizagem específicos, nos quais é preciso ampliar a cidadania (que não é plena) e, com suas ofertas, incrementar a empregabilidade. Também ganha novos contornos o velho modelo dos quatro pilares - escola, formação profissional, escolas superiores e educação de adultos - ao mesmo tempo em que aumentam, conforme as indicações do Programa Internacional de Avaliação de Alunos (PISA), as possibilidades da transferência de experiências pedagógicas entre os subsistemas, assim como entre eles e as experiências não-formais e informais.

A nova carta política da Comissão da União Europeia destaca o significado atribuído à educação de adultos na educação ao longo da vida. Esse significado encontra uma avaliação muito positiva no informe da comissão, chamado "Educação de adultos: a formação profissional não tem fim". ${ }^{10}$ Foram ali formuladas cinco teses fundamentais:

1. superação das insuficiências no acesso;

2. garantia de qualidade na educação de adultos;

3. reconhecimento e valoração dos resultados da aprendizagem;

4. investimento em pessoas idosas e em migrantes;

5. indicadores e pontos de referência (benchmarking).

A comissão deveria elaborar o que seria específico para a educação de adultos no contexto da educação

\footnotetext{
${ }^{9}$ www.europa.eu.int

${ }^{10}$ European Parliament resolution of 16 January 2008 on adult learning: It is never too late to learn (2007/ 2114(INI)).
} 
ao longo da vida, assim como indicar aos Estadosmembros uma perspectiva político-pedagógica, além de concretizá-la em um plano de ação. Esse documento foi então votado com o título de Plano de ação para a educação de adultos: sempre é tempo de aprender (European Commission, 2007). No processo de consulta, três elementos-chave fortemente interconectados são destacados:

- as políticas adotadas que venham ao encontro das necessidades e demandas da sociedade e da economia;

- a política de governo que inclua qualidade, eficiência e viabilidade econômica da educação de adultos;

- os sistemas ativos que incluam atividades de ensino, suporte para ele e reconhecimento dos efeitos da aprendizagem, com foco na motivação e nas necessidades de aprendizagem, sempre no contexto das necessidades e demandas da sociedade e da economia.

Finalmente, deveriam ser unificados os cinco setores do plano de ação a serem apoiados pela Comissão da União Europeia e pelos Estados-membros:

- análise dos efeitos das reformas na educação de adultos dos Estados membros, nos setores educacional e de qualificação;

- incremento da qualidade do financiamento da educação de adultos;

- reforço nas chances dos adultos para obter um degrau a mais, ou seja, alcançar qualificação pelo menos um nível acima do anterior;

- aceleração do processo de aferição de habilidades e competências sociais, de forma que se busque validade e reconhecimento dos efeitos produzidos pela aprendizagem;

- monitoramento mais eficaz da educação de adultos.

A DVV posicionou-se com muita clareza em relação a esse processo, ante o governo federal: "Es- peramos da política nacional, nos planos nacional, regional e municipal, que seja reconhecido o valor do amplo e profissional sistema da educação de adultos elaborado pela União Europeia e a educação ao longo da vida como o quarto pilar do sistema educacional, construindo-o e fortalecendo-o". ${ }^{11}$

O processo de elaboração do informe desenvolveu-se paralelamente aos estudos que, conforme o plano original, uma vez concluído, deveriam operar como ponto de partida. Conforme a visão da Associação Europeia de Educação de Adultos (EAEA), de fato houve um paralelismo entre os processos e eventualmente mesmo uma inter-relação. No total foram quatro rascunhos, preparados pelos colaboradores da União Europeia em conjunto com a EAEA, relacionados aos resultados do estudo e sua respectiva discussão. Não se pode negar a recíproca influência nesse processo. "A educação de adultos é uma chave e um elemento vital da educação ao longo da vida” é uma afirmação bastante contundente, que seria muito bom que estivesse outra vez presente nos compromissos das políticas educacionais, tanto no plano nacional, quanto nos planos estadual e local.

\section{Tendências e questões da educação de adultos na Europa}

É comum que os documentos orientadores sejam precedidos de estudos preparatórios, o que aconteceu nesse caso; a Comissão da União Europeia produziu vários. Especialmente interessantes foram o estudo produzido pela EAEA, em agosto de 2008, Tendências e questões da educação de adultos na Europa, e outro sobre os mais importantes órgãos que oferecem programas de educação de adultos na Europa. No primeiro caso, a EAEA assumiu, por meio de seu então presidente, Janos Toth, a liderança do consórcio, contando com vários parceiros: o professor Joachim

${ }^{11}$ Auf dem Wege zu einem Aktionsplan für Erwachsenenbildung `It is always a good time to learn`. Erklärung des DVV anläßlich der deutschen Ratspräsidentschaft. Siehe www.dvvinternational.de. 
Knoll atuou como especialista independente, Susanne Lattke representava a DIE, e pela DVV estava Heribert Hinzen, que naquele tempo exercia a vice-presidência da EAEA.

Também é comum dispor-se de pouco tempo e poucos recursos para esse tipo de estudo e é regra geral o resultado final ser pouco compensador em relação ao sacrifício, mas o produto final é compensador. Não foi diferente nesse caso. Entre a proposta de trabalho e sua conclusão decorreram não mais que seis meses, nos quais foi alcançado o resultado previsto, que pode ser encontrado em versão integral, entre diversos documentos, na página www.eaea.org, assim como a versão original em inglês, publicada com apoio da União Europeia (EAEA, 2006).

O estudo explora aspectos políticos, legais e financeiros, discute motivos da não-participação e também da ampliação do acesso, sugere questões para a geração de talentos e de qualificações-chave, discute certificação e creditação, lança luzes sobre a qualidade da formação profissional inicial e continuada e propõe fortes conexões entre demografia e migrações. No capítulo final, apresenta cinco mensagens-chave a serem apoiadas e concretizadas, ao lado de muitas conclusões e proposições, que assim se apresentam:

- uma perspectiva política holística, total, integrada, sistêmica e de longo alcance para a educação de adultos e respectivo financiamento;

- fundos públicos especialmente destinados aos marginalizados, com uma sólida infraestrutura local;

- qualidade dos recursos e do pessoal envolvido;

- reconhecimento e creditação da educação não-formal e informal em paralelo à educação formal de adultos;

- indicadores-chave simples, sustentados e ao mesmo tempo colaborando com pesquisas e estatísticas.

O estudo foi publicado em diversos idiomas, tendo sido bastante divulgado e atraído muita atenção.

\section{Considerações finais}

Para concluir, atenho-me a alguns poucos, mas importantes aspectos. Como o paradigma da educação ao longo da vida se impôs? Como se deve refletir a partir dele sobre a educação de adultos? Que significado foi atribuído às estruturas? Quais variações são oferecidas e discutidas, ao se levar em conta o "triângulo de ouro” da educação de adultos na política, na legislação e no financiamento?

Não é difícil observar que esta pequena série de questões deixa de lado outras não menos importantes, como qualidade, formação profissional inicial e continuada, pesquisa, acesso e objetivos coletivos.

No texto, ocupei-me principalmente dos contextos europeu e alemão. Mas a UNESCO é uma instituição que se orienta de forma global. Certamente as conferências preparatórias, a exemplo da europeia, foram bem-sucedidas, o que se pode observar pelos documentos conclusivos. Um objetivo importante da VI CONFINTEA, por meio de medidas obrigatórias, é aumentar as oportunidades futuras de sucesso e realização por meio das políticas de formação, de garantia financeira e legal e de contínuo desenvolvimento profissional.

Ao mesmo tempo, os países ricos e também os organismos de desenvolvimento devem comprometerse a apoiar as nações pobres na consecução desses objetivos. Milhões de crianças, jovens e adultos que não escrevem e não leem - ou o fazem de forma precária - também devem encontrar algo de útil na CONFINTEA VI.

As expectativas em relação ao evento são tão grandes quanto diversas, conforme as situações e as perspectivas. Elas dizem respeito aos governos das nações industrializadas, passando pelas organizações não-governamentais dos países em desenvolvimento mais pobres, chegando às instituições multilaterais. O lado positivo disso tudo é que, de todos os pontos de vista, o reconhecimento do significado da educação de jovens e adultos na educação ao longo da vida, depois de um período de muita dureza, voltou a crescer. 


\section{Referências bibliográficas}

ALDRIDGE, Fiona; HAYLEY, Lamb; ALAN, Tucket. Are we closing the gap? A NIACE briefing on participation in learning by adults from minority ethnic groups. Leicester: NIACE, 2008. BMBF. Konzeption der Bundesregierung zum Lernen im Lebenslauf. Deutscher Bundestag. Ausschuss für Bildung, Forschung und Technikfolgenabschätzung. A-Drs. 16(18)353. Acesso em: 6 maio 2008.

CERI - Centre for Educational Research and Innovation. Recurrent education. A strategy for lifelong learning. Paris: OCDE, 1973. COUNCIL OF THE EUROPEAN UNION. Draft Council Conclusions of 22 May 2008 on adult learning. 9205/08, EFUC 143, SOC 275. Brussels, 8 maio 2008.

DVV. Lifelong Learning - Need and Funding. Answers to questions for the hearing of $29^{\text {th }}$ January 2007, Committee for Education Research and the Implications of Technology, German Parliament, A-Drs. 16(18) 144. Adult Education and Development, n. 68, p. 123-140, 2007.

EAEA. Adult Education Trends and Issues in Europe. Restricted tender no. EAC/43/05 as completed by $11^{\text {th }}$ of August 2006. Brussels: EAEA, 2006.

Statement. Pan-European VI Confintea VI Preparatory Conference, Brussels, Budapest, nov. 2008.

EUROPEAN COMMISSION. Communication from the Commission. Making a European lifelong learning a reality, COM 2001, 678 final. 2001.

. Communication from the Commission to the Council. Action Plan on Adult Learning. It is always a good time to learn. The European Parliament, the European Economic and Social Committee and the Committee of the Regions. COM 2007, 558 final. Brussels, 27 set. 2007.

FAURE, Edgard et al. Learning to be. The world of education today and tomorrow. Paris: UNESCO, 1972.
KEOGH, Helen. Adult learning and education in the Unesco region of Europe, North America and Israel. Summary Report. In: CONFINTEA, 6., Regional Preparatory Conference for Europe, North America and Israel, 2008, Budapest. Budapest: s.ed., 3-5 dez. 2008. KNOLL, Joachim H. Internationale Weiterbildung und Erwachsenenbildung. Konzepte: Institutionen, Methoden. Darmstadt, 1996. Zur Geschichte der Unesco-Weltkonferenzen für Erwachsenenbildung - von Helsingör (1949) bis Hamburg (1997). Bildung und Erziehung, p. 129-149, 2/2008.

LÜBKE, Oliver S. European developments in adult learning policy. Supplementary statement. Bonn: BMBF, 2008 Man

SEITTER, Wolfgang. Geschichte der Erwachsenenbildung. Eine Einführung. Bielefeld: Bertelsmann, 2000.

UNESCO. Disponível em: <http://www.unesco.org/education/uie/ confintea/documents.html>. Disponível em: <http://www.unesco.org/en/confintea $>$.

HERIBERT HINZEN, doutor em ciências sociais pela Universidade de Heidelberg (Alemanha), é diretor do DVV International, o Instituto para Cooperação Internacional da Associação Alemã de Educação de Adultos, e professor honorário das Universidades de Pécs (Hungria) e Iasi (Romênia). Publicações mais recentes: em coedição com Hanno Schindele: Capacity building and the training of adult educators (IPE 52. Bonn: DVV, 2006); em coedição com Chris Duke: Knowing more, doing better. Challenges for VI CONFINTEA from Monitoring EFA in Nonformal Youth and Adult Education (IPE 58. Bonn: DVV, 2008); em coedição com Beate Schmidt-Behlau: The right to education in the context of migration and integration (IPE 59. Bonn: DVV, 2008). E-mail: hinzen@dvv-international.de

Recebido em fevereiro de 2009

Aprovado em março de 2009 
freireano de educación, visando contribuir para la construcción de la ciudadanía y la participación. El desafío para la CONFINTEA VI es construir síntesis capaces de llevar a consensos sobre contenidos y métodos de educación de jóvenes y adultos, además de atender a las urgencias, mirando la educación no como costo o inversión, sino como derecho y servicio, y promover la construcción de espacios públicos en los que se erija la totalidad social con la especificidad de cada grupos, en el contexto del multiculturalismo.

Palabras claves: educación de jóvenes y adultos; nuevos paradigmas; multiculturalismo.

John Aitchison

\section{A voz do Sul na CONFINTEA VI: a} agenda da África

O texto é uma síntese da agenda africana para a CONFINTEA VI, preparada a partir de relatórios nacionais trazidos pelos 46 países africanos reunidos em Nairóbi, Quênia, em novembro de 2008. Depois de breve descrição de um contexto desencorajador, o autor elenca as questões que foram consideradas prioritárias quanto à estrutura, gestão, financiamento e qualidade da educação de adultos na África. Diante da constatação de que os problemas da área são massivos, abrangentes e sistêmicos, os representantes reunidos em Nairóbi sugeriram maior intercâmbio entre países e a formação de um grupo de alto nível, multissetorial, que levantasse fundos para o financiamento da educação de adultos na África. Além disso, recomendaram que a CONFIN-

TEA VI tivesse uma orientação voltada para resultados e para ação e que fosse estabelecido um sistema efetivo de acompanhamento da implementação das deliberações tomadas.

Palavras-chave: educação de adultos na África; CONFINTEA VI.
The South speaking to CONFINTEA VI: the African agenda

The text is a synthesis of the African agenda for CONFINTEA VI based on national reports prepared by 46 African countries present in Nairobi, Kenya, in November 2008. After a brief description of the discouraging context, the author lists the questions which were considered priority with regard to structure, management, financing and quality of adult education in Africa. Faced with the affirmation that the problems of the area are massive, wide-ranging and systemic, the representatives present in Nairobi suggested greater exchange between countries and the creation of a multi-sectoral high level group to raise funds for the financing of adult learning and education in Africa. In addition, they recommended that CONFINTEA VI should be oriented towards results and action and that an effective system for monitoring the implementation of the deliberations taken should be established.

Key words: adult education in Africa; CONFINTEA VI.

\section{La voz del Sur en la CONFINTEA} VI: la agenda de África

El texto es una síntesis de la agenda africana para la CONFINTEA VI, preparada a partir de informes nacionales traídos por los 46 países africanos reunidos en Nairobi, Kenia, en noviembre de 2008. Después de de una breve descripción de un contexto desencorajador, el autor numera las cuestiones que fueron consideradas prioritarias en cuanto a la estructura, gestión, financiamiento y calidad de la educación de adultos en África. Delante de la constatación de que los problemas del área son masivos, abrangentes y sistémicos, los representantes reunidos en Nairobi sugirieron un mayor intercambio entre países y la formación de un grupo de alto nivel, multisectorial, que levantara fondos para el financiamiento de la educación de adultos en África. Además de esto, recomendaron que la CONFINTEA VI tuviera una orientación apuntada para resultados y para acción, y que fuera establecido un sistema efectivo de acompañamiento de la implementación de las deliberaciones tomadas.

Palabras claves: educación de adultos en África; CONFINTEA VI.

Heribert Hinzen

Educação de adultos

ao longo da vida: desenvolvimentos atuais e interdependentes na Alemanha e na Europa, a caminho da VI CONFINTEA

A educação e a aprendizagem de adultos têm recebido mais atenção e reconhecimento a partir do conceito de aprendizagem ao longo da vida, que se torna agora o principal paradigma para a teoria e a prática educacionais. Este movimento se acentua no contexto de organismos como a UNESCO, a União Europeia e a Associação Alemã de Educação de Adultos (DVV), no caso da Alemanha. Há claras indicações de que cada um desses organismos exerce mútua influência sobre os outros, por meio das políticas, programas, modelos e até mesmo pela administração de recursos financeiros. Isto é exemplificado no artigo pela indicação de processos que vêm ganhando importância nos últimos anos, na preparação da VI Conferência Mundial de Educação de Adultos - VI CONFINTEA.

Palavras-chave: educação de adultos na Europa; VI CONFINTEA.

Lifelong Adult

education: current and

interdependent developments in

Germany, Europe and elsewhere, on the road to CONFINTEA VI

Adult learning and education

has received more attention and recognition since the dissemination of the concept of lifelong learning, which 
has now become the major paradigm within educational theory and practice. This is even more so in the context of organizations like UNESCO, the European Union and the German Adult Education Association (DVV). There are clear indications that these levels - global, regional and national - and their respective organizations influence each other via policies, programmes, models and even funding procedures. This is exemplified here by looking at processes that have been gaining importance in the last few years as part of the preparation for the coming VI International Conference on Adult Education - VI CONFINTEA.

Key words: adult education in Europe; VI CONFINTEA.

Educación de adultos

a lo largo de la vida: desarrollos actuales e en Alemania, en Europa y fuera de ella, en el camino de la VI CONFINTEA

La educación y aprendizaje de adultos ha recibido más atención y reconocimiento a partir del concepto de aprendizaje a lo largo de la vida, que se vuelve ahora el principal paradigma para la teoría y práctica de educaciones. Este movimiento se destaca en el contexto de organismos como UNESCO, la Unión Europea y la Asociación Alemana de Educación de Adultos - DVV, en el caso de Alemania. Hay indicaciones claras de que cada uno de esos organismos ejerce mutua influencia en los otros, por medio de las políticas, programas, modelos y hasta mismo por la administración de recursos financieros. Esto es ejemplificado en el artículo por la indicación de procesos que vienen teniendo importancia en los últimos años, en la preparación de la próxima conferencia mundial de educación de adultos, la VI CONFINTEA.

Palabras claves: educación de adultos en Europa; CONFINTEA VI.
Sérgio Haddad

A participação da sociedade civil brasileira na educação de jovens e adultos e a CONFINTEA VI

Este artigo tem por objetivo discutir a participação da sociedade civil no contexto da VI CONFINTEA e as questões trazidas no seu processo preparatório.

Para tanto, história como veio se dando esta participação ao longo da história recente do Brasil, em diálogo com a constituição das políticas públicas em educação de jovens e adultos (EJA), discutindo a relação entre o poder público e a sociedade civil. Retoma o processo preparatório relativo à $\mathrm{V}$ CONFINTEA, ocorrida em 1997, em Hamburgo, na Alemanha, e a consequente formação dos fóruns estaduais de educação de jovens e adultos e dos encontros nacionais desses fóruns, os Enejas, conformando um modo particular de participação.

Palavras-chave: VI CONFINTEA; participação da sociedade civil.

Civil society participation in adult and youth education and the VI

\section{CONFINTEA}

The objective of this article is to discuss civil society participation in the context of the VI CONFINTEA and questions to which the preparatory process has given rise. To that end, it recounts the way in which this participation has occurred in recent Brazilian history in dialogue with the constitution of public policies of adult and youth education, whilst discussing the relation between public power and civil society. It goes back to the preparatory process for CONFINTEA V, which took place in Hamburg (Germany) in 1997 and the resulting creation of the state forums of adult and youth education and the national meetings of these forums - ENEJAS, giving expression to a particular type of participation.

Key words: VI CONFINTEA; civil society participation.
La participación de la sociedad civil en la educación de jóvenes y adultos y la VI CONFINTEA

Este artículo tiene por objetivo discutir la participación de la sociedad civil en el contexto de la CONFINTEA VI y las cuestiones traídas en su proceso preparatorio. Por tanto, relata la historia de como vino dándose esta participación a lo largo de la historia reciente de Brasil, en diálogo con la constitución de las políticas públicas en educación de jóvenes y adultos (EJA), discutiendo la relación entre el poder público y la sociedad civil. Retoma el proceso preparatorio relativo a la CONFINTEA V, ocurrido en 1997, en Hamburgo, en Alemania, y la consecuente formación de los foros estaduales de educación de jóvenes y adultos y de los encuentros nacionales de estos foros, los ENEJAs, conformando un modo particular de participación. Palabras claves: VI CONFINTEA; Brasil; participación; sociedad civil.

Nilton Bueno Fischer

Educação não-escolar de adultos e educação ambiental: um balanço da produção de conhecimentos

O objetivo do artigo é analisar a produção de conhecimento presente na relação entre os campos da educação de adultos e educação ambiental em projetos e práticas não-escolares, explicitada em 39 dissertações e teses produzidas em universidades brasileiras entre 1988 e 2006. A análise das dissertações e teses reafirma a necessidade da escuta dos sinais da natureza pela voz das pessoas das classes populares em suas interações em diferentes práticas sociais, dados os novos desafios postos pelo desdobramento das "intervenções” do homem no equilíbrio das relações homem-natureza. No balanço da produção ficou evidenciada, de forma predominante, uma intencionalidade dos pesquisadores em 